\title{
Assessment of Magnitude and Associated Factors of Adverse Birth Outcomes among Deliveries at Suhul Hospital Shire, Tigray, Ethiopia From September, 2015 to February, 2016
}

\author{
Tesfay Adhena ${ }^{1}$, Abera Haftu ${ }^{2 *}$ and Brhane Gebreegziabher ${ }^{2}$ \\ ${ }^{1}$ Midwifery Department, Axum University, Ethiopia \\ ${ }^{2}$ Midwifery Department, Mekele University, Ethiopia
}

Received: December 15, 2017; Published: December 21, 2017

*Corresponding author: : Abera Haftu, Midwifery Department, Mekele University, Ethiopia

\section{Abstract}

Introduction: Adverse birth outcomes such as prematurity, low birth weight and still birth represent significant problems in both developing and developed countries. Each year, about 15 million babies in the world, more than one in 10 births, are born too prematurely. More than one million of those babies die shortly after birth; countless others suffer from lifelong physical, neurological, or educational disabilities, often at great cost to families and societies.

Objectives: Assessment of magnitude and associated factors of neonatal adverse birth out comes among deliveries at Suhul Hospital, Shire, Tigray, Ethiopia from September, 2015 to February, 2016

Methodology: An institution based cross sectional study with retrieving of information from cards retrospectively was conducted at maternity ward of Suhul hospital from September, 2015 to February, 2016. Simple random sampling method was used. Data was analyzed using SPSS version 20. Logistic regression analyses were used to identify significant predictors of adverse birth outcomes. P-value $\leq 0.05$ was considered as statistically significant. Odds ratio was also used to determine the strength of association between independent variables and the birth outcomes.

Results: The magnitude of adverse birth outcome among the study participants were $96(22.6 \%)$. Out of 425 births $37(8.7 \%)$ were preterm birth, $49(11.5)$ were low birth weight and 41(9.6\%) were still birth. Induced onset of labor (AOR=3.09, (95\%) CI: 1.501-6.346), hypertensive disorders of pregnancy (AOR=6.368, (95\%) CI: 2.880-14.080), ante partum hemorrhage (AOR=3.087, (95\%) CI: 1.172-8.132), previous bad obstetric history (AOR=2.290, (95\%) CI 1.165-4.503) and multiple pregnancies (AOR=7.230, CI: 2.973-17.580) were significantly associated with adverse birth outcomes.

Conclusion: the magnitude of adverse birth outcome among the study participants was higher than the WHO estimation. Induced onset of labor, hypertensive disorders of pregnancy, ante partum hemorrhage, previous bad obstetric history and multiple pregnancies were the major predictors of adverse birth outcomes and improving of maternal health care service requires strict attention.

Keywords: Adverse birth outcome; Preterm birth; Still birth; Low birth weight

\section{Introduction}

Adverse birth outcomes such as prematurity, low birth weight and birth defects- represent significant problems in both developing and developed countries. Each year, about 15 million babies in the world, more than one in 10 births, are born too prematurely. More than one million of those babies die shortly after birth; countless others suffer from lifelong physical, neurological, or educational disabilities, often at great cost to families and societies [1]. Globally, an estimated 13 million babies are born before 37 completed weeks of gestation annually. Rates are generally highest in low and middle income countries and increasing in some middle and high-income countries. Complications of preterm birth are the leading direct causes of neonatal mortality and account for an estimated $27 \%$ of neonatal deaths. This comes to almost four million neonatal deaths every year [2]. From a global standpoint, the prevalence rate of preterm birth varies from 47.5 to 137 per 1000 live births. Grand multiparty, a previous history of preterm birth or abortion, younger maternal age, inadequacy of prenatal care, reported hypertension, ante partum hemorrhage, premature rupture of fetal membranes and induced labor are significant determinants of preterm birth $[3,4]$.

Worldwide stillbirth rate has declined by $14 \%$, from 22.1 stillbirths per 1000 births in 1995 to 18.9 stillbirths per 1000 births in 2009. But in the African region, there was only an annual decline of less than $1 \%$. The stillbirth rate for developed countries 
is estimated between 4.2 and 6.8 per 1000 births, whereas for the developing world, the estimate ranges from 20 to 32 per 1000 births. Two thirds of all stillbirths occur in just two regions: SouthEast Asia and Africa [5,6]. In sub-Saharan Africa, an estimated 900,000 babies die as stillbirths. It is estimated that babies who die before the onset of labor, or ante partum stillbirths, account for two-thirds of all stillbirths in countries where the mortality rate is greater than 22 per 1,000 births [7]. From previous studies, preterm birth, increasing maternal age, history of stillbirth, reported hypertension, extremes of neonatal birth weight, cesarean delivery, operative vaginal delivery, and assisted breech delivery were all significantly associated with still birth [8]. According to Ethiopian Demographic and Health Survey in 2011, In Ethiopia, high rate of neonatal mortality (37 deaths per 1,000 live births)is reported and preterm birth is believe to be a major and direct cause of neonatal mortality [9]. In Ethiopia, adverse outcome of pregnancy are still major public health problems $[10,11]$.

Adverse birth outcomes are the most important vital statistics used to assess maternal and child health program. They are indicator of the quality of antenatal care, medical services and general health services to the mother and the children [12]. Epidemiological data on the magnitude and risk factors of adverse birth outcomes are important for planning maternal and child health care services in developing countries. Most of the newborns who are admitted in neonatal wards are secondary to preterm birth and low birth weight. Most of them are also complicated with various health problems after they have been admitted with a diagnosis of either low birth weight or preterm birth. Mothers are also feeling unhappiness and become unsatisfactory after having a still birth [13]. Hence, this study aimed to determine magnitude and associated factors of adverse birth outcomes of pregnancy at a Suhul Hospital Tigray Ethiopia. The result of this study will serves as a baseline for other wide studies as well as for planning health intervention to improve the wellbeing of children and women [14-19].

\section{Conceptual Frame Work}

This frame work was developed by the principal investigator by reviewing different literatures and books (Figure 1).

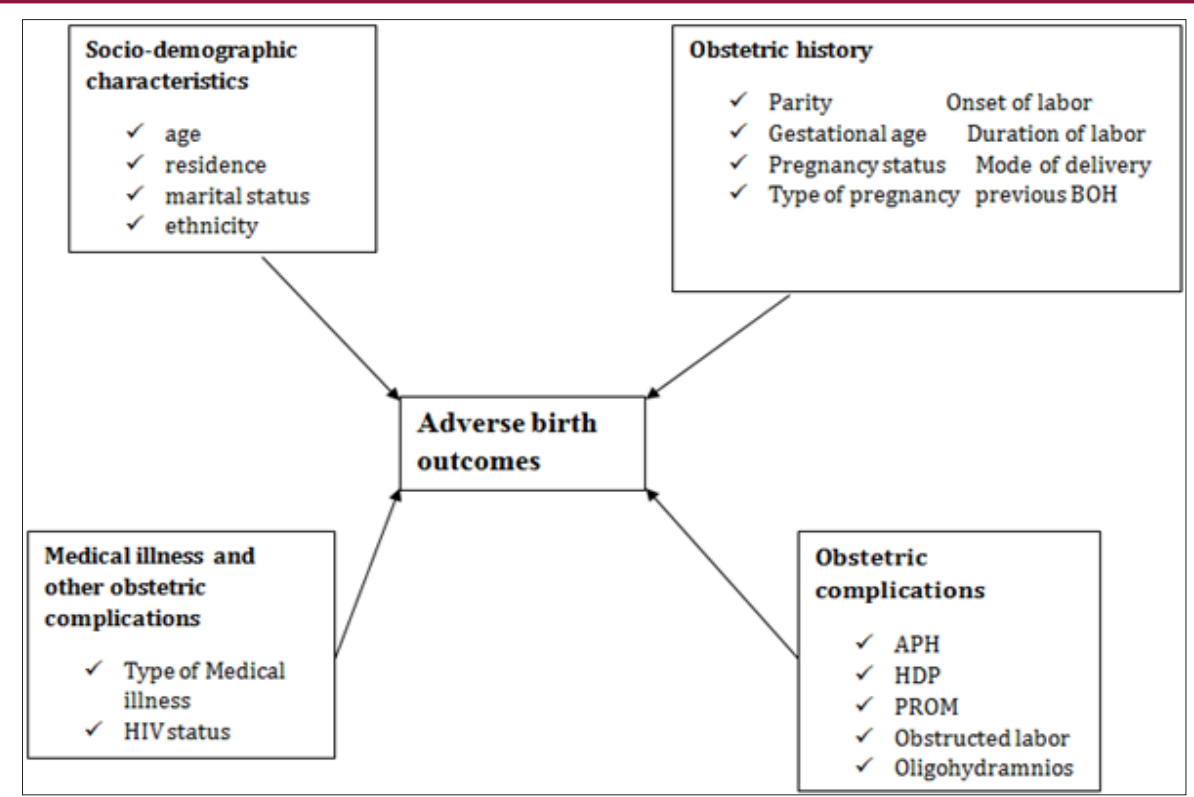

Figure 1: Conceptual frame work of adverse birth outcomes and associated factors at suhul hospital from September, 2015 to February 2016.

\section{Subjects and Methods}

This was a cross sectional study conducted at Shire (Suhul) Hospital. Shire city is located in western zone of Tigray with an area of $30.0316 \mathrm{~km}^{2}$ and total population of 47,284 . It is $1100 \mathrm{KM} \mathrm{km}$ far from the capital city of Ethiopia, Addis Ababa and 283km from Mekelle, which is a capital city of Tigray. The study was conducted between June 15 -July 15, 2016. The study population was sampled term new born babies delivered at Adwa General Hospital for the period July 1, 2014 to June 30, 2016. Individual term new born babies reviewed from mother's chart or cards.

Source Population: were all mothers who gave birth at Suhul hospital from September, 2015 to February, 2016.

Study Population: selected cards of those mothers who gave birth at Suhul hospital from September, 2015 to February, 2016.
Study Unit: Maternal cards with adverse birth outcomes and normal birth out come.

Inclusion Criteria: All maternal cards with adverse birth outcomes and normal birth outcomes with no missing the most important information (detail records on demographic characteristics, current obstetric history, medical history and past obstetric history and delivery summary) were included.

Exclusion Criteria: maternal cards with birth outcomes of congenital anomaly.

Sampling and Sample Size Determination: The sample size was determined by using single proportion for finite population with $95 \%$ confidence interval, marginal error (d) of $4 \%$.

$$
\mathrm{n}=\left(\mathrm{z}^{2} \mathrm{p}(1-\mathrm{p})\right) / \mathrm{d}^{2}
$$




\section{$\mathrm{n}=$ Sample size}

$\mathrm{z}=$ the standard score (critical value) corresponding to $95 \%$ confidence level $=1.96$.

$\mathrm{d}=$ the proportion of sampling error between the sample and the population $=4 \%(0.04)$.

$\mathrm{p}=$ prevalence

Calculation of the sample size was based on the Gondar's prevalence which is as follows:

$$
(1.96)^{2} *(230 / 1000) *(770 / 1000)=425
$$

Simple random sampling technique and card reviewing method was used. In Suhul hospital there were a total of $1590(\mathrm{~N})$ deliveries from September 1, 2015 to February 30, 2016. The sample size was 425 (n). After identifying the number of cards at each month the calculated sample size was distributed to each month of study based on population proportion size and the study subjects were nominated randomly (Figure 2).

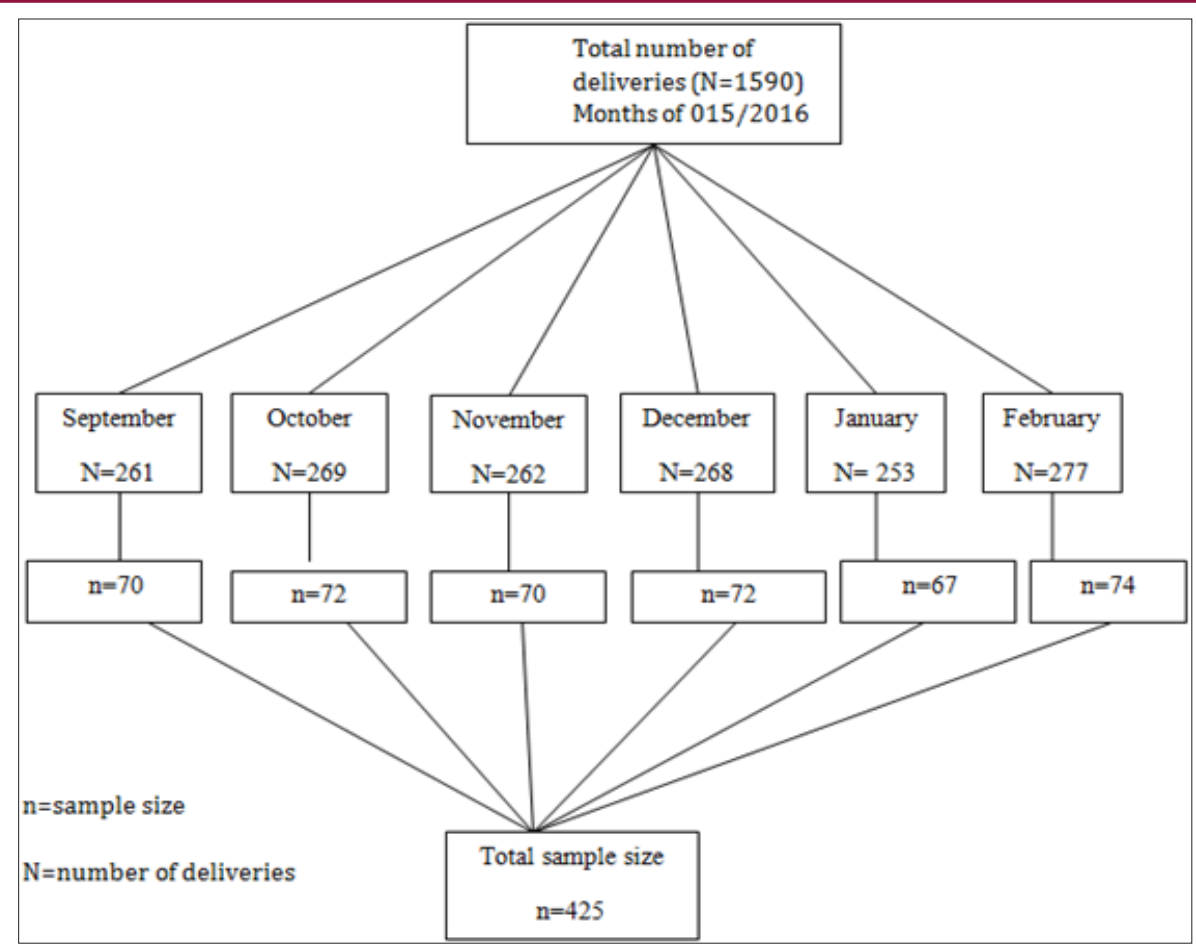

Figure 2: Sampling frame work of study participants.

Data Collection Methods: Since the file is kept at record office after discharge, data collection was done using structured checklist from clinical records of mothers' (registration books and individual cards). Cases was identified from the records office through reviewing every record of women who gave birth at Suhul hospital from September 1, 2015 to February 30, 2016.The checklist was structured into four logical sections (socio demographic characteristics, obstetrics related factors; medical history and birth outcomes assessment). Data were collected by 3BSc midwives after giving 2 days training.

Data Quality Control: Data quality was ensured during collection, coding, entry and analysis. Pre prepared Structured checklist was used. Training was given to the data collectors and supervisors to prevent any confusion and have a common understanding about the study. Each card was checked for its consistency, provision of full information and appropriate documentation. Pretest was conducted on 21 maternal cards (with adverse birth outcome and normal birth outcome) that gave birth before September 2015. Based on the pretest modification on logical sequence, simplicity, and clarity of checklist had been done. Supervision of data collectors included observation of how the data collectors will collect data was done by supervisors. The data collectors were instructed to write cards number on the check list during the data collection so that any identified errors was traced back using the cards number. The filled checklist was checked for completeness by data collectors, supervisors and PI on a daily basis. Consequently, any problem encountered was discussed among the team and solved immediately. The collected data code was given to the completed questionnaire. The data was entered and analyzed using SPSS version 20 statistical package. Data cleaning was performed to check for frequencies, accuracy, and consistencies and missed values and variables. Any error identified was corrected.

Data Analysis: Frequencies, proportion and summary statistics were used to describe the study population in relation to relevant variables. Both Bivariate and multivariate logistic regression analysis was used to determine the association of each independent variable with the dependent variable. Variables significant in Bivariate analysis were entered into a multivariate logistic regression model to adjust the effects of cofounders on the outcome variable. Odds ratio with $95 \%$ confidence intervals was computed to identify the presence and strength of association, and statistical significance was declared if $\mathrm{p}<0.05$. 


\section{Study Variables}

1. Dependent variable

- Adverse birth outcomes (Still birth, preterm birth and LBW)

\section{Independent variables}

3. Socio demographic characteristics

- $\quad$ Residence, age, marital status and ethnicity

\section{Obstetric history}

- Parity, gestational age, onset of labor, duration of labor pregnancy status, mode of delivery, type of pregnancy, previous poor obstetric history, contraceptive use

\section{Medical illness and other obstetric complications}

- Anemia, UTI, Malaria, HIV/AIDS, Hypertension, Ante partum hemorrhage, HIV status, ART status, Hepatitis virus screening.

\section{Operational Definitions}

1. Adverse birth outcome: newborns delivered as preterm, low birth weight or still ssbirth

2. Still birth: fetal loss after 28 wks of gestational age and during intra partum period.

\section{Ethical Consideration}

Ethical clearance was obtained from Mekelle University College of health science. Purpose of the study was informed for the managers, staff members and health professionals who were working at Suhul hospital.

\section{Dissemination And Utilization Of Results}

Results will be disseminated to Mekelle University, Tigray region health bureau and to Suhul hospital where the data had been collected.

Table 1: Socio-demographic characteristics.

\begin{tabular}{|c|c|c|c|}
\hline Characteristics & & Frequency (n) & Percentage (\%) \\
\hline \multirow{2}{*}{$\begin{array}{c}\text { Residence } \\
(\mathrm{n}=425)\end{array}$} & Rural & 234 & 55 \\
\cline { 2 - 4 } & Urban & 191 & 45 \\
\hline \multirow{4}{*}{ Age } & $<20$ & 48 & 11.3 \\
\cline { 2 - 4 } & $20-34$ & 283 & 66.6 \\
\cline { 2 - 4 } & $>34$ & 94 & 22.2 \\
\hline \multirow{3}{*}{ Marital status } & Married & 375 & 88.2 \\
\cline { 2 - 4 } & Single & 36 & 8.5 \\
\cline { 2 - 4 } & Divorced & 14 & 3.3 \\
\hline \multirow{3}{*}{ Ethnicity } & Tigrai & 378 & 88.9 \\
\cline { 2 - 4 } & Amhara & 41 & 9.6 \\
\cline { 2 - 4 } & Other & 6 & 1.4 \\
\hline
\end{tabular}

\section{Result}

The Socio-Demographic Characteristics Of Women Attended Maternity Ward At Suhul Hospital, Shire, Tigray, Ethiopia: A total of 425 cards of mothers were reviewed in the study of which 283 $(66.6 \%)$ were in the age group of $20-34$, followed by $94(22.2 \%)$ greater than 34 years with the mean age of 29 and standard deviation of +7 . Majority of the mothers 375 (88.2) were married and more than half of mothers $234(55 \%)$ were urban residents. Regarding their ethnicity majority, 378 (88.9) of them were Tigrai followed by 41 (9.6\%) were Amhara [20] (Table 1).

The Obstetrics Characteristics Of Women Attended Maternity Ward At Suhul Hospital, Shire, Tigray, Ethiopia: More than half of mothers $246(57.9 \%)$ were multipara and $119(28 \%)$ of mothers were Primipara. Most of the mothers, 407(95.8\%) had history of ANC follow up, almost half of them 201(49.4\%) had their first ANC visit during first trimester and 191(46.9\%) mothers had at least four visits during current pregnancy. with regard to the status of current pregnancy $325(76.5 \%)$ of the pregnancies were wanted and planned. In this study majority of mothers 391(92\%) were supplemented with Iron and Folic acid during ANC follow up. Majority of the mothers 392 (92.2\%) had taken TT vaccination, of them around one third of the mothers had taken the fifth dose of TT vaccination. Regarding the type of pregnancy in this study $401(94.3 \%)$ of the pregnancy were singleton. The mean duration of labor was 13 hours with standard deviation of +4 . More than three fourth of $350(82.4 \%)$ onset labor were spontaneous and majority of mothers $322(75.8 \%)$ were delivered by SVD. Two third of mothers had used contraceptives prior this pregnancy, of them 204(72.1\%) had taken inject able (Table 2).

Table 2: Obstetrics characteristics.

\begin{tabular}{|c|c|c|c|}
\hline Characteristics & & Frequency (n) & $\begin{array}{c}\text { Percentage } \\
(\%)\end{array}$ \\
\hline \multirow{2}{*}{ ANC follow up } & Yes & 407 & 95.8 \\
\hline & No & 18 & 4.2 \\
\hline \multirow{3}{*}{$\begin{array}{l}\text { Time of first ANC } \\
\text { visit }(n=407)\end{array}$} & First trimester & 201 & 49.4 \\
\hline & $\begin{array}{l}\text { Second } \\
\text { trimester }\end{array}$ & 171 & 42.2 \\
\hline & Third trimester & 35 & 86 \\
\hline \multirow{4}{*}{$\begin{array}{l}\text { Number of ANC } \\
\text { visit }(n=407)\end{array}$} & One & 9 & 2.2 \\
\hline & Two & 66 & 16.2 \\
\hline & Three & 141 & 34.6 \\
\hline & Four & 191 & 46.9 \\
\hline \multirow{3}{*}{ Parity } & Primipara & 119 & 28 \\
\hline & Multipara & 246 & 57.9 \\
\hline & Grand multipara & 60 & 14.1 \\
\hline \multirow{4}{*}{ Gestational age } & Preterm & 35 & 8.2 \\
\hline & Term & 323 & 76 \\
\hline & Late term & 47 & 11.1 \\
\hline & Post term & 20 & 4.7 \\
\hline \multirow{3}{*}{ Pregnancy status } & $\begin{array}{c}\text { Planned and } \\
\text { wanted }\end{array}$ & 327 & 76.5 \\
\hline & $\begin{array}{l}\text { Unplanned but } \\
\text { wanted }\end{array}$ & 47 & 12.7 \\
\hline & $\begin{array}{l}\text { Unplanned and } \\
\text { unsupported }\end{array}$ & 46 & 10.8 \\
\hline
\end{tabular}




\begin{tabular}{|c|c|c|c|}
\hline \multirow{2}{*}{$\begin{array}{l}\text { Iron and folic acid } \\
\text { supplementation }\end{array}$} & Yes & 391 & 92 \\
\hline & No & 34 & 8 \\
\hline \multirow{2}{*}{ TT vaccination } & Yes & 392 & 92.2 \\
\hline & No & 33 & 7.8 \\
\hline \multirow{6}{*}{$\begin{array}{c}\text { Dose of TT } \\
\text { vaccination } \\
(n=392)\end{array}$} & One & 24 & 6.1 \\
\hline & Two & 96 & 24.6 \\
\hline & Three & 85 & 21.7 \\
\hline & Four & 47 & 12 \\
\hline & Five & 118 & 30.2 \\
\hline & Booster & 22 & 5.6 \\
\hline \multirow{2}{*}{$\begin{array}{l}\text { Type of } \\
\text { pregnancy }\end{array}$} & Singleton & 399 & 93.9 \\
\hline & Multiple & 26 & 6.1 \\
\hline \multirow{2}{*}{ Onset of labor } & Spontaneous & 350 & 82.4 \\
\hline & Induced & 75 & 17.6 \\
\hline \multirow{4}{*}{ Mode of delivery } & SVD & 322 & 75.8 \\
\hline & $\begin{array}{l}\text { Instrumental } \\
\text { delivery }\end{array}$ & 56 & 13.2 \\
\hline & $\mathrm{C} / \mathrm{S}$ & 44 & 10.4 \\
\hline & $\begin{array}{l}\text { Destructive } \\
\text { delivery }\end{array}$ & 3 & 0.7 \\
\hline \multirow{2}{*}{$\begin{array}{c}\text { Contraceptive } \\
\text { prior current } \\
\text { pregnancy }\end{array}$} & Yes & 283 & 66.6 \\
\hline & No & 142 & 33.4 \\
\hline \multirow{3}{*}{$\begin{array}{c}\text { Type of } \\
\text { Contraceptive } \\
(n=283)\end{array}$} & Depo-Provera & 204 & 72.1 \\
\hline & Implanon & 57 & 20.1 \\
\hline & Other & 22 & 7.8 \\
\hline \multirow{4}{*}{$\begin{array}{l}\text { Previous poor } \\
\text { obstetric history }\end{array}$} & No & 248 & 78.7 \\
\hline & Perinatal death & 24 & 7.6 \\
\hline & Abortion & 42 & 13.3 \\
\hline & $\begin{array}{l}\text { Preterm and } \\
\text { low birth } \\
\text { weight }\end{array}$ & 1 & 0.3 \\
\hline
\end{tabular}

Table 3: Medical illness and obstetric complications.

\begin{tabular}{|c|c|c|c|}
\hline Variables & & Frequency(n) & $\begin{array}{c}\text { Percentage } \\
\text { (\%) }\end{array}$ \\
\hline \multirow{4}{*}{ Medical illness } & Yes & 52 & 12.2 \\
\cline { 2 - 4 } & No & 373 & 87.8 \\
\hline \multirow{4}{*}{$\begin{array}{c}\text { Type of medical } \\
\text { illness (n=52) }\end{array}$} & Anemia & 7 & 13.5 \\
\cline { 2 - 4 } & MTlaria & 16 & 30.8 \\
\cline { 2 - 4 } & DM & 10 & 13.5 \\
\hline \multirow{3}{*}{$\begin{array}{c}\text { Hypertensive } \\
\text { disorder }\end{array}$} & HIV/AIDS & 12 & 19.2 \\
\cline { 2 - 4 } & Yes & 37 & 23 \\
\hline \multirow{3}{*}{$\begin{array}{c}\text { Type of HTN } \\
\text { (n=37) }\end{array}$} & Preeclampsia & 23 & 8.7 \\
\cline { 2 - 4 } & Eclampsia & 6 & 16.3 \\
\cline { 2 - 4 } & Chronic HTN & 5 & 13.51 \\
\cline { 2 - 4 } & gestational HTN & 3 & 8.11 \\
\hline \multirow{2}{*}{\begin{tabular}{c} 
APH \\
\cline { 2 - 4 }
\end{tabular}} & Yes & 32 & 7.5 \\
\cline { 2 - 4 } & No & 393 & 92.5 \\
\hline
\end{tabular}

\begin{tabular}{|c|c|c|c|}
\hline \multirow{4}{*}{$\begin{array}{c}\text { Type of APH } \\
\text { (n=32) }\end{array}$} & $\begin{array}{c}\text { undetermined } \\
\text { origin }\end{array}$ & 20 & 62.5 \\
\cline { 2 - 4 } & $\mathrm{AP}$ & 7 & 21.9 \\
\cline { 2 - 4 } & $\mathrm{PP}$ & 5 & 15.6 \\
\hline \multirow{4}{*}{$\begin{array}{c}\text { Other obstetric } \\
\text { complications }\end{array}$} & No & 389 & 91.5 \\
\cline { 2 - 4 } & Oligohydramnios & 27 & 6.4 \\
\cline { 2 - 4 } & Uterine rupture & 2 & 1.4 \\
\hline \multirow{3}{*}{ HIV screening } & Yes & 345 & 0.5 \\
\cline { 2 - 4 } & No & 80 & 81.2 \\
\hline \multirow{2}{*}{$\begin{array}{c}\text { HIV status } \\
\text { (n=345) }\end{array}$} & Reactive & 35 & 18.8 \\
\cline { 2 - 4 } & Non-reactive & 310 & 10.1 \\
\hline \multirow{2}{*}{ ART status } & Started & 33 & 89.9 \\
\cline { 2 - 4 } & Not started & 2 & 94.3 \\
\hline \multirow{2}{*}{ Hepatitis virus } & Yes & 28 & 6.7 \\
\cline { 2 - 4 } & No & 397 & 6.6 \\
\hline \multirow{2}{*}{ Syphilis } & Yes & 7 & 93.4 \\
\cline { 2 - 4 } & No & 418 & 1.6 \\
\hline
\end{tabular}

The Medical Illness And Obstetric Complications Among Women Attended Maternity Ward at Shire Suhul Hospital Tigray Ethiopia: Fifty two $(12.2 \%)$ of the mothers had medical illness, of them $16(38.2 \%)$ mothers had urinary tract infections. thirty seven $(8.7 \%)$ and thirty two $(7.5 \%)$ of mothers had hypertensive disorders of pregnancy and ante partum hemorrhage respectively. Twenty seven $(6.4 \%)$ of mothers also had premature rupture of membrane during current pregnancy. More than three-quarter 345(81.2) of mothers were screened for HIV, of them $35(10.1 \%)$ were reactive for HIV test and 33(94.3\%) of them had started HAART. All study participants were screened for hepatitis viral infection and syphilis, $28(6.6 \%)$ and $7(1.6 \%)$ of mother had positive results for hepatitis and syphilis respectively (Table 3 ).

The ABO Among Women Attended Maternity Ward at Shire Suhul Hospital Tigray Ethiopia: The study finding showed that the prevalence of ABO among the study participant was 96(22.6\%). Seven $(14.3 \%)$ of low birth neonates and six $(16.2 \%)$ of preterm births were still birth and $23(47 \%)$ of LBW neonates were preterm. almost half of the new born 213(50.1\%) were males. The mean weight of newborns was $2.9 \mathrm{~kg}$ with the standard deviation of + $0.6 \mathrm{~kg}$ (Figure 3).

Factors Associated With Adverse Birth Outcome Among Women Attended Maternity Ward at Shire Suhul Hospital Tigray Ethiopia: Bi-variate and multivariate logistic regressions were done to assess the predictors of $\mathrm{ABO}$. Onset of labor, residence, hypertensive disorders of pregnancy, ante partum hemorrhage, PROM, previous BOH and type of pregnancy were significant at bi variate logistic regression with $\mathrm{p}$ value of less than 0.05 . In the multivariate analysis the factors that remained significantly associated with $\mathrm{ABO}$ were Onset of labor, hypertensive disorders of pregnancy, ante partum hemorrhage, previous $\mathrm{BOH}$ and type of pregnancy. Induced on set of labor were 3 times (AOR=3.09, (95\%) CI: 1.501-6.346) more likely odds associated with $\mathrm{ABO}$ than spontaneous on set 
labor. Mothers who had HDP were 6 times (AOR=6.368, (95\%) CI: 2.880-14.080) more likely odds associated with ABO than mother without HDP. Women who had APH during respective pregnancy were 3 times (AOR=3.087, (95\%) CI: 1.172-8.132) more likely odds associated with ABO than women who didn't face APH. Mothers who had previous history of BOH were 2.3 times (AOR=2.290, (95\%) CI 1.165-4.503) more likely odds associated with ABO than mothers who hadn't bad obstetric history. Multiple pregnancies were 7 times (AOR: 7.230, 95\%) CI 2.973-17.580) more likely odds associated with ABO than singleton pregnancy (Table 4).

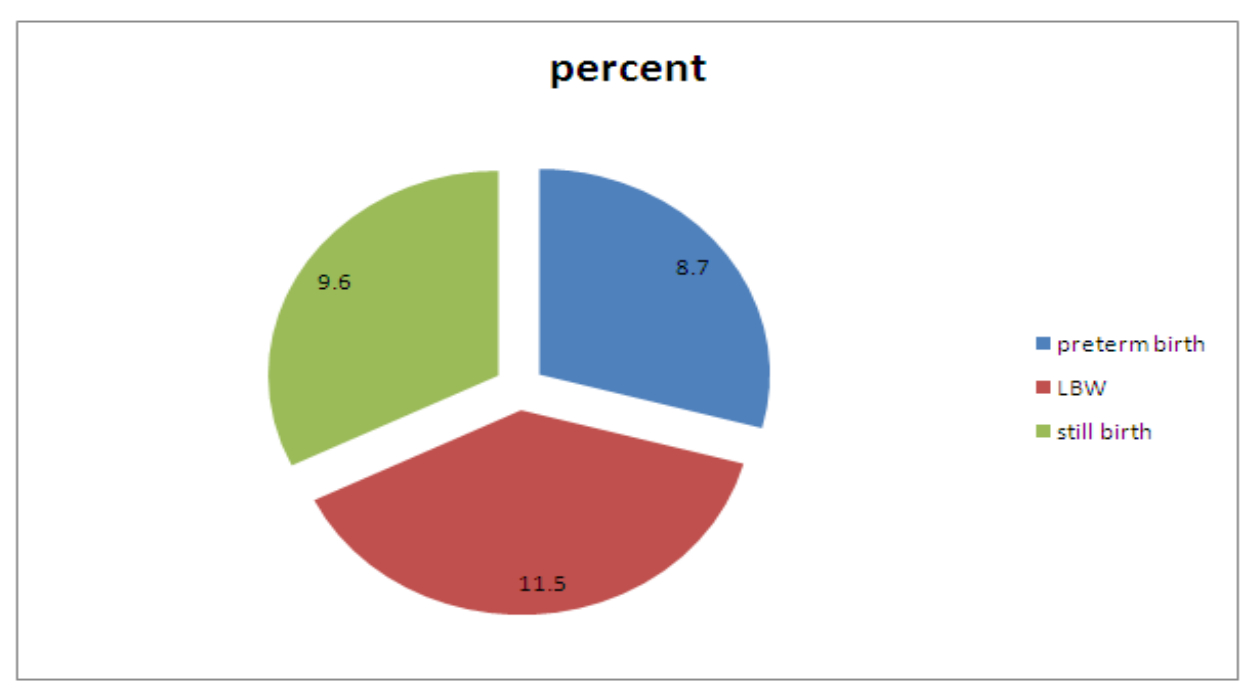

Figure 3: Magnitude of preterm birth, LBW and still birth.

Table 4: Logistic regression analysis of variables associated adverse birth outcomes.

\begin{tabular}{|c|c|c|c|c|c|}
\hline \multirow[t]{2}{*}{ Variables } & & \multicolumn{2}{|c|}{ Adverse birth outcome } & \multirow[t]{2}{*}{ COR(95\% CI } & \multirow[t]{2}{*}{ AOR (95\%) CI } \\
\hline & & No & Yes & & \\
\hline \multirow{2}{*}{ Onset of labor } & Spontaneous & 293 & 57 & 1 & 1 \\
\hline & Induced & 36 & 39 & $5.569(3.263-9.505)$ & $3.09(1.501-6.346)^{*}$ \\
\hline \multirow{2}{*}{ Residence } & Rural & 169 & 65 & 1. $985(1.229-3.206)$ & $1.643(.932-2.895)$ \\
\hline & Urban & 160 & 31 & 1 & 1 \\
\hline \multirow{2}{*}{ HDP } & Yes & 13 & 24 & $8.103(3.937-16.677)$ & $6.368(2.880-14.080)^{*}$ \\
\hline & No & 316 & 72 & 1 & 1 \\
\hline \multirow{2}{*}{$\mathrm{APH}$} & Yes & 13 & 19 & $5.998(2.839-12.674)$ & $3.087(1.172-8.132)^{*}$ \\
\hline & No & 316 & 77 & 1 & 1 \\
\hline \multirow{2}{*}{ PROM } & Yes & 17 & 12 & $2.622(1.205-6.339)$ & $2.549(1.025-6.339)$ \\
\hline & No & 312 & 84 & 1 & 1 \\
\hline \multirow{2}{*}{$\mathrm{BOH}$} & Yes & 37 & 30 & $3.587(2.068-6.222)$ & $2.290(1.165-4.503)^{*}$ \\
\hline & No & 292 & 66 & 1 & 1 \\
\hline \multirow{2}{*}{ Type of pregnancy } & Singleton & 317 & 82 & 1 & 1 \\
\hline & Multiple & 12 & 14 & $4.510(2.010-10.122)$ & $7.230(2.973-17.580)^{*}$ \\
\hline
\end{tabular}

\section{Discussion}

The finding of this study showed that the magnitude of $\mathrm{ABO}$ among deliveries was $96(22.5 \%)$ among which the prevalence of still birth was $41(96 / 1000$ births) and the magnitude of preterm birth and low birth weight were $37(8.7 \%)$ and $49(11.5)$ respectively. The prevalence is higher than the WHO estimation [20-22] and regional and worldwide estimation [5] of adverse birth outcomes this variation may be due to the difference that this study was institution based study and which was done in a zonal hospital, so that the magnitude may increase because of increasing number of referral cases from health centers and primary hospitals. The magnitude was also higher than studies done in Tanzania [23],
Iran [24], China [25] and Ghana [26]. The variations between the findings may be attributable to the variations in methodological and socio-economic variations, quality of maternal health service and facilities explain differences in adverse birth outcomes in respective study areas.

The findings of this study were lower than from pervious reported studies in Jimma zone [27], Debremarkos [28,29] and Kersa east Ethiopia [30]. This variation may be due to methodological difference that the previous studies were used prospective study but in this study the methodology used was card review, hence it may limit the type and number of adverse birth outcomes. The Figure were also lower than the study findings 
done in north wello zone [31], this variation is attributable to the previous study was community based study. It were also a little beat lower than the study done in Gondar which showed that the prevalence of adverse birth outcome was $23 \%$ with the proportion of $14.3 \%, 11.2 \%$ and $7.1 \%$ preterm birth, low birth weight and still birth respectively [32]. This variation may due to methodological difference. Pregnancy induced hypertension one of the risk factors for adverse birth outcome and mother with HDP was 21.6 times more likely to associate with adverse birth outcome than mother without HDP. This finding was in line with other studies done in Iran [24]. Similar finding was also reported from the study done in India [33] which revealed that mothers with PIH were more likely to delivery adverse birth outcome as compared with those women without PIH.

This is again supported by a research done in Tanzania [34], China [25], Gondar [32], and Debremarkos [28]. This might be due to hypertension results in decreased blood flow through the spiral arterioles and decreased delivery of oxygen and nutrients to the placenta and fetus and Hypertension also might be associated with placental infarction. These researchers indicated that hypertensive disorders might play a critical role in the incidence of adverse birth outcome as supported by other studies. Evidence from earlier study showed that reduced placental blood flow leads to decreased fetal growth, with an increased risk of intrauterine growth restriction and low birth weight [29]. In this study Ante-partum hemorrhage during the current pregnancy is significantly associated with adverse birth outcomes this finding was in line with the previous studies in Iran [24], Tanzania [34] and Pakistan [35]. Similar study in Gondar also reported that Ante-partum hemorrhage is significantly associated with adverse birth outcomes, bleeding during pregnancy is one of the etiologies of anemia leading to intrauterine oxygen inadequacy [32].

Furthermore, mothers who had previous history of poor obstetric history were 2.3 times more likely to have adverse birth out comes than mothers who hadn't bad obstetric history. This Figure was similar with previous study findings in Tanzania [23], Iran [30], China [25], Gondar [32], and north wello zone [31]. This might be due to most poor obstetrics histories are recurrent. Induced on set of labor was also significantly associated with a adverse birth out comes this may be due to different maternal and fetal indications like hypertensive disorders of pregnancy, ante partum hemorrhage, oligohydramnios, premature rupture of membrane etc, in order to prevent maternal and fetal complications. Multiple pregnancies were significantly associated with adverse birth outcomes. Similar studies in jimma zone [27] and Canada [9] also revealed Multiple pregnancies were risk factors for development of adverse birth outcome this might be due to chorionicity, in monochorionic placentation is associated with fetal mortality and morbidity in monochorionic twins the placenta is shared and inter twin vascular anastamoses, which produce various degree of twin to twin transfusion syndrome in $10 \%$ to $15 \%$ cases. Twin to twin transfusion syndrome causes discordant twin growth and, sometimes intrauterine demise of one twin. It may also result in fetal anemia or it may be related to uterine distension, increased intrauterine volume, or related complications such as cervical incompetence [9].

\section{Conclusion}

The magnitude of adverse birth outcome among the study population was higher than WHO estimation. Induced onset of labor, hypertensive disorders of pregnancy, ante partum hemorrhage, previous bad obstetric history and multiple pregnancies were the major predictors of adverse birth outcomes.

\section{Acknowledgment}

We would like to express our appreciation to Mekele University and the Department of Midwifery for their invaluable contribution towards the completion of this study. We also thank our friends and colleagues for their critical contributions.

\section{References}

1. Althabe F, Bhutta Z, Blencowe H, Chandra-Mouli V, Chou D, et al. (2012) In Born too soon: The global action report on preterm birth. Edited by Christopher Howson MK, Joy L Geneva, (Eds.) WHO, Switzerland.

2. Lawn JE, Gravett MG, Nunes TM, Rubens CE, Stanton C (2010) Global report on preterm birth and stillbirth (1 of 7): definitions, description of the burden and opportunities to improve data. In Maryland, USA: The Johns Hopkins Bloomberg School of Public Health BMC Pregnancy Childbirth 10(1): 1.

3. WHO, March of Dimes, Partnership for Maternal, Newborn \& Child Health, Save the Children. Born too soon: the global action report on preterm birth.

4. Liu L, Liu JM, Liu YH, Li ZW, Ye RW, et al. (2007) Prevalence of preterm birth among singletons in 10 counties (cities) of China, 1993-2005. Zhonghua Liu Xing Bing XueZa Zhi 28(11): 1051-1054.

5. Say L (2011) In National, regional, and worldwide estimates of stillbirth rates in 2009 with trends since 1995. Edited by WHO DoRHaR. WHO, Geneva, Switzerland.

6. Smith GC, Fretts RC (2007) Stillbirth. Lancet 370(9600): 1715-1725.

7. Lincetto O, Mothebesoane-Anoh S, Gomez P, Munjanja S (2011) Chapter 2; Antenatal Care: Opportunities for Africa's Newborns. WHO, Geneva, Switzerland.

8. Stringer EM, Vwalika B, Killam WP, Giganti MJ, Mbewe R, et al. (2011) Determinants of stillbirth in Zambia. Obstet Gynecol 117(5): 1151-1159.

9. Follow up issues with multiples Aideen M Moore, karel Obrien pediatric child health 2006;11(5): 283-286.

10. Andargie G, Berhane Y, Worku A, Kebede Y (2013) Predictors of perinatal mortality in rural population of Northwest Ethiopia: a prospective longitudinal study. BMC public health 13: 168.

11. Beck S, Wojdyla D, Say L, PilarBetran A, Merialdi M, et al. (2010) The world wide incidence of preterm birth: a systematic review of maternal mortality and morbidity. Bull World Health Organ 88(1): 31-38.

12. Wardlaw T, Blanc A, Zupan J, Åhman E (2004) Low birth weight: country, regional and global estimates. United Nations Children's Fund and World Health Organization, New York, USA. 
13. Dasgupta A, Basu R (2010) Determinants of low birth weight in a Block of Hooghly, West Bengal: a multivariate analysis. Int J Biol Med Res 2(4): 838-842.

14. WHO Nutrition and food safety, WHO country cooperation strategy Ethiopia 2008-2011, 12-13

15. Ramakrishnan U (2004) Nutrition and low birth weight. American Journal of Clinical Nutrition 79(1): 17-21.

16. Badshah S, Mason L, McKelvie K, Payne R, Lisboa P (2008) Risk factors for low birth weight in the public-hospitals at Peshawar, NWFP-Pakistan. BMC Public Health 8: 197.

17. Gravett MG, Robens CE, (2010) Global report on preterm and still birth. BMC pregnancy child birth $10(1)$.

18. World health organ under five mortality Ethiopia. Bulletin 31.

19. Steer P (2005) The epidemiology of preterm labor. BIOG 112: 1-3.

20. (2008) America's Children and the Environment ( $3^{\text {rd }}$ edn.).

21. Atossa Rahmanifar (2007) Trends in Birth Outcomes and Maternal Characteristics in Indiana Statistics from the Live Birth Data 1990-2005. Indiana State Department of Health, Maternal and Children's Special Health Care Services.

22. Lawn JE, Blencowe H, Pattinson R, et al. (2011) Stillbirths: Where? When? Why? How to make the data count? Lancet 377(9775): 14481463.

23. Deborah Watson-Jones, Helen A Weiss ,John M Changalucha, James Todd, Balthazar Gumodoka, et al. (2007) Adverse birth outcomes in United Republic of Tanzania impact and prevention of maternal risk factors 85 : 9-18.

24. Rahele A Sadegh H, Mehrdad D, Farhad Pourfarzi (2014) Prevalence and risk factors associated with preterm birth in Ardabil. IranReprod Med 12(1): 47-56.

25. Chen Y, Li G, Ruan Y (2011) An epidemiological survey on low birth weight infants in china and analysis of outcomes of full term low birth weight infants. BMC pregnancy child birth 13:242.

26. Ntui A sundep, April P. Carson, Cornelius Archer Turpin, Berhanu Tameru, Ada T Agidi, et al. (2013) Determinants of access to antenatal careand birth outcomes in Kumasi, Ghana. journal of epidemiology and global health 3(4): 279-288.
27. Tema T (2006) Prevalence and determinants of low birth weight injimma zone, southwest ethiopia. East African Medical Journal 83: 366-371.

28. Tigist Bekele, Abdela Amanon, Kahsay Zenebe Gebreslasie (2013) Preterm Birth and Associated Factors among Mothers Who gave Birth in Debremarkos Town Health Institutions.

29. Lema Desalegn (2015) Determinants Of Low Birth Weight In Debre Berehan Referal Hospital, North Shoa Zone, Amhara Regional State, Ethiopia, BMC.

30. Nega Assefa, Yemane Berhane, Alemayehu Worku, Amy Tsui (2012) The hazard of pregnancy loss and stillbirth among women in Kersa, East Ethiopia, BMC 107-112.

31. Asmamaw Eshete, Dereje Birhanu, Belaynew Wassie (2013) Birth outcomes among laboring mothers in selected health facilities of North Wollo Zone, Northeast Ethiopia: A facility based cross-sectional study 5(7): 1141-1150.

32. kilew Awoke Adane, Tadesse Awoke Ayele, Leta Gedefaw Ararsa, Bikes Destaw Bitew, Berihun Megabiaw Zeleke (2014) Adverse birth outcomes among deliveries at Gondar University Hospital, Northwest Ethiopia 14(90): 1471-2393.

33. Mousumi G (2014) Association of Maternal Age and Low Socio-Economic Status of Women Birth Outcome, International Research Journal of Social Scienceso INDIA 3(10): 21-27.

34. Modesta Mitao, Rune Philemon, Joseph Obure, Blandina T Mmbaga, Sia Msuya, et al (2015) Risk factors and adverse perinatal outcome associated with low birth weight in Northern Tanzania: a registry-based retrospective cohort study. Asian Pascific Journal of Reproduction 5(1): 75-79.

35. Hossain N, Khan N, Khan NH (2009) Obstetric causes of still birth at low socioeconomic setting. JMPA 59(11): 744-747.

36. Taffa N, Obare F (2004) Pregnancy and child health outcomes among adolescents in Ethiopia. The Ethiopian Journal of Health Development 18: $90-95$.

37. Prianka Mukhopadhyay, RN Chaudhuri, Bhaskar Paul (2010) Hospitalbased Perinatal Outcomes and Complications in Teenage Pregnancy in India. J Health Popul Nutr 28(5): 494-500. 